\title{
Ultrasound-guided topographic anatomy of the medial calcaneal branches of the tibial nerve
}

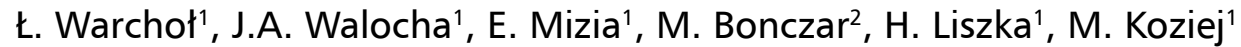 \\ ${ }^{1}$ Department of Anatomy, Jagiellonian University Medical College, Krakow, Poland \\ 2Intermed Medical Clinic, Zabierzow, Poland
}

[Received: 4 April 2020; Accepted: 26 May 2020]

Background: The purpose of this study was to evaluate the topographic anatomy of the tibial nerve and its medial calcaneal branches in relation to the tip of the medial malleolus and to the posterior superior tip of the calcaneal tuberosity using the ultrasound examination and to verify its preoperative usefulness in surgical treatment.

Materials and methods: Bilateral ultrasound examination was performed on 30 volunteers and the location of the tibial nerve bifurcation and medial calcaneal branches origin were measured. Medial calcaneal branches were analysed in reference to the amount and their respective nerves of origin.

Results: In $77 \%$ of cases, tibial nerve bifurcation occurred below the tip of the medial malleolus with the average distance of $5.9 \mathrm{~mm}$ and in $48 \%$ of cases above the posterior superior tip of the calcaneal tuberosity with the average distance of $2.7 \mathrm{~mm}$. In $73 \%$ of cases medial calcaneal branches occurred as a single branch originating from the tibial nerve (60\%). The average distance of the first, second and third medial calcaneal branch was accordingly $9.3 \mathrm{~mm}$ above, $9.5 \mathrm{~mm}$ below and $11.6 \mathrm{~mm}$ below the tip of the medial malleolus and $17.7 \mathrm{~mm}$ above, $1.6 \mathrm{~mm}$ below and $4 \mathrm{~mm}$ below the posterior superior tip of the calcaneal tuberosity.

Conclusions: As the tibial nerve and its branches present a huge variability in the medial ankle area, in order to prevent the iatrogenic injuries, the preoperative or intraoperative ultrasound assessment (sonosurgery) of its localisation should be introduced into the clinic. (Folia Morphol 2021; 80, 2: 267-274)

Key words: medial calcaneal nerve, ultrasound-guided nerve examination, tarsal tunnel syndrome, medial plantar nerve, lateral plantar nerve, sonosurgery

\section{INTRODUCTION}

The tibial nerve arises as a branch of the sciatic nerve bifurcation in the popliteal fossa. It runs distally on the tibialis posterior muscle together with the posterior tibial vessels. Usually at the level of flexor retinaculum it terminally divides into lateral and medial plantar nerve. During distal course, the tibial nerve emits medial calcaneal branches which are variable in number and origin. The tibial nerve and its branches provide innervation to the posterior lower leg, foot and sole muscles and the skin of medial foot and sole [28].

Address for correspondence: Dr. Ł. Warchoł, Department of Anatomy, Jagiellonian University Medical College, ul. Kopernika 12, 31-034 Kraków, Poland, tel: +48 601865 239, e-mail: I.warchol@uj.edu.pl

This article is available in open access under Creative Common Attribution-Non-Commercial-No Derivatives 4.0 International (CC BY-NC-ND 4.0) license, allowing to download articles and share them with others as long as they credit the authors and the publisher, but without permission to change them in any way or use them commercially. 


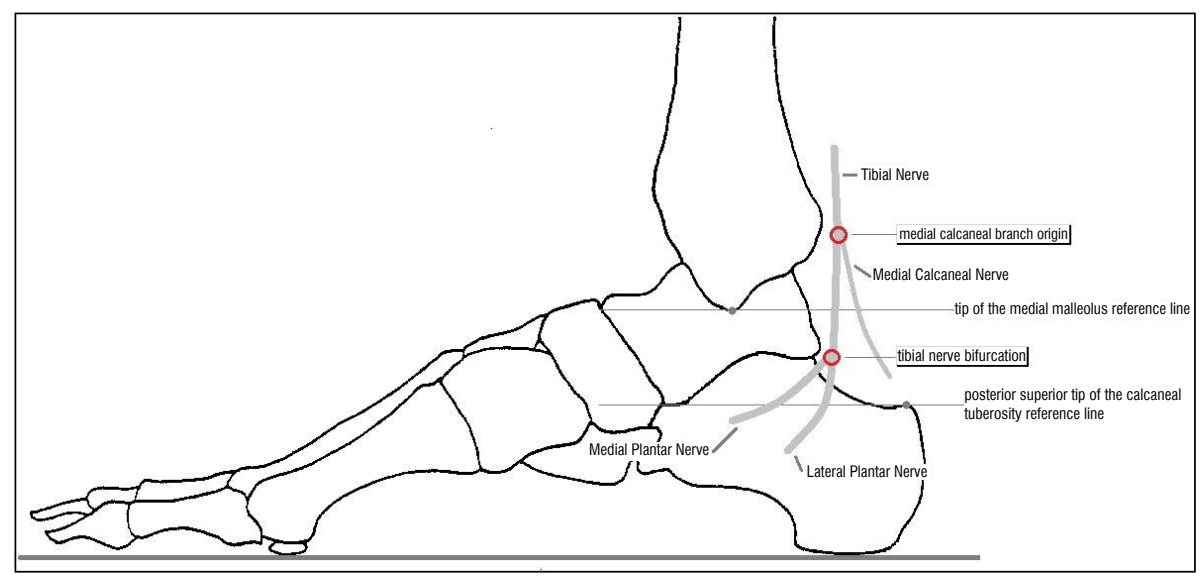

Figure 1. Foot scheme with the measured points and the reference lines.
The knowledge of topographic anatomy of peripheral neurovascular bundles is important in surgical procedures, especially in the medial ankle surgery. It helps to understand the pathophysiology of the tarsal tunnel syndrome and its symptoms such as heel and sole burning pain, paraesthesia and numbness radiating to the toes and proximally on the medial side of the calf with often nocturnal presentation $[2,5,22,24,25,39]$. The tibial nerve and its branches may be entrapped in the tarsal tunnel by various internal and external mechanisms [8]. Additionally other medical conditions with body fluid retention and chronic inflammatory processes may lead to nerve compression [13]. Rising prevalence of diabetes mellitus contributes to a large number of compression syndromes [36]. Currently, popular outdoor activities (e.g. jogging) also bring new cases of foot pain [23].

One of the utmost treatment options for the foot pain syndromes is a surgery $[1,20]$. It must be performed with the highest awareness of tibial nerve anatomy without inflicting iatrogenic damage. According to anatomy books, atlases and cadaveric dissection studies, the tibial nerve presents a various pattern of its bifurcation as well as origin and number of medial calcaneal branches $[6,7,9-11,14-17,21,27$, $30,31,33]$. In relation to the anatomical landmarks we tried to establish the most common topographic localisation of the tibial nerve and its final branches and to encourage to the preoperative ultrasound examination prior to medial ankle surgeries.

\section{MATERIALS AND METHODS}

Patients. The study was conducted on the 30 volunteers ( $n=60$ lower limbs). There were 16 females and 14 males. The average age of the volunteers was 25.7 years (range 19-50 years). The inclusion criteria were as follows: age 18 years or older, written informed consent for the examination. The exclusion criteria were: any lower limb trauma, surgical or radiotherapeutic procedures of the lower limb, deformation of the lower limb, and chronic disease of the lower limb.

The ultrasound examination was performed on the Mylab Gold 25 ultrasound scanner with an $18 \mathrm{MHz}$ linear probe (penetration depth $3.0 \mathrm{~cm}$ ) in the Department of Anatomy between December 2016 and April 2017. The examination and measurements were performed by an orthopaedic surgeon with more than 20 years of experience in ultrasound examination.

The ultrasound examination was performed with the volunteer lying prone with the foot in neutral position (ankle fixed in the foot stabilising device and adjusted to the right angle). Each procedure was initiated $40 \mathrm{~cm}$ proximally to the tip of the medial malleolus, continuing distally along the tibial nerve course up to its bifurcation and further looking for medial malleolus branches. Following points were marked on the skin with the fine tip skin marker: the tibial nerve bifurcation point, medial calcaneal branches origin, the tip of the medial malleolus and the posterior superior tip of the calcaneal tuberosity (attachment point of the Achilles tendon to the calcaneal tuberosity). Lines crossing the marked points were drawn parallel to the foot plane (Fig. 1). Distances from the reference lines (the tip of the medial malleolus line and the posterior superior tip of the calcaneal tuberosity) to the tibial nerve bifurcation line and to the medial calcaneal branches origin lines were measured with the calliper. If the measured point was below the reference line the value is in negative numbers, if above the reference line the value is in positive number. Medial calcaneal branches were analysed with regards to the number of branches, nerve of origin and relation to the ref- 
Table 1. Tibial nerve bifurcation location according to the reference line

\begin{tabular}{lcc}
\hline Location & Tip of the medial malleolus & Posterior superior tip of the calcaneal tuberosity \\
\hline Above the reference line & $14(23.3 \%)$ & $23(38.3 \%)$ \\
At the level of the reference line & $0(0.0 \%)$ & $8(13.3 \%)$ \\
Below the reference line & $46(76.7 \%)$ & $29(48.3 \%)$ \\
\hline
\end{tabular}

Table 2. Results of measurements [mm] and statistics

\begin{tabular}{|c|c|c|c|c|c|c|c|c|c|c|}
\hline $\begin{array}{l}\text { Reference } \\
\text { line }\end{array}$ & Measure & point & $\mathbf{N}$ & $\begin{array}{l}\text { Mean } \pm \text { stand- } \\
\text { ard deviation }\end{array}$ & Median & Maximum & Minimum & $\begin{array}{c}\text { Lower } \\
\text { quartile (01) }\end{array}$ & $\begin{array}{c}\text { Upper } \\
\text { quartile (03) }\end{array}$ & $\begin{array}{l}\text { Sex differ- } \\
\text { ences }\end{array}$ \\
\hline \multirow{4}{*}{$\begin{array}{l}\text { Tip of the } \\
\text { medial } \\
\text { malleolus }\end{array}$} & \multicolumn{2}{|c|}{ Tibial nerve bifurcation } & 60 & $-5.93 \pm 19.59$ & -8.00 & 60 & -33 & -19.50 & -1.50 & $P=0.6929$ \\
\hline & \multirow{3}{*}{$\begin{array}{l}\text { Medial calca- } \\
\text { neal branch } \\
\text { origin }\end{array}$} & $1^{\text {st }}$ branch & 60 & $9.27 \pm 61.73$ & -1.00 & 337 & -27 & -7.00 & 6.50 & $P=0.9409$ \\
\hline & & $2^{\text {nd }}$ branch & 16 & $-9.50 \pm 10.09$ & -8.50 & 2 & -35 & -14.00 & -0.50 & \\
\hline & & $3^{\text {rd }}$ branch & 4 & $-11.75 \pm 9.03$ & -11.00 & -4 & -21 & -19.50 & -4.00 & \\
\hline \multirow{4}{*}{$\begin{array}{l}\text { Posterior } \\
\text { superior } \\
\text { tip of the } \\
\text { calcaneal } \\
\text { tuberosity }\end{array}$} & \multicolumn{2}{|c|}{ Tibial nerve bifurcation } & 60 & $2.67 \pm 19.79$ & 0.00 & 72 & -26 & -10.00 & 7.50 & $P=0.6776$ \\
\hline & \multirow{3}{*}{$\begin{array}{l}\text { Medial calca- } \\
\text { neal branch } \\
\text { origin }\end{array}$} & $1^{\text {st }}$ branch & 60 & $17.67 \pm 61.18$ & 7.00 & 343 & -17 & 3.00 & 13.50 & $P=0.8939$ \\
\hline & & $2^{\text {nd }}$ branch & 16 & $-1.63 \pm 11.28$ & -1.00 & 12 & -29 & -6.50 & 8.00 & \\
\hline & & $3^{\text {rd }}$ branch & 4 & $-4.00 \pm 8.45$ & -2.50 & 3 & -14 & -11.00 & 3.00 & \\
\hline
\end{tabular}

erence lines. The results were transformed into rates and tabulated.

\section{Statistical analysis}

Obtained data was statistically processed using descriptive statistics such as percentage, mean, standard deviation. A p-value of $<0.05$ was considered as statistically significant. Two groups were compared using the Mann-Whitney test or t-test depending normal distribution. All analyses were performed using MedCalc version 16.8.

The research protocol was approved by the local Ethics Committee (registry no. 122.6120.315.2016). The study was performed in accordance with the ethical standards established in the 1964 Declaration of Helsinki and its later amendments. The volunteers were informed about the study protocol and gave both informed and written consent to participate in the study.

\section{RESULTS}

There were 30 volunteers ( $n=60$ lower limbs) with an average age of $25.7 \pm 7$ amongst which 32 (53.3\%) were female and 28 (46.7\%) male feet.

The bifurcation of the tibial nerve into the medial and lateral plantar nerve most frequently occurred below the tip of the medial malleolus (76.7\%) with the mean distance of $5.93 \pm 19.59 \mathrm{~mm}$ and above the posterior superior tip of the calcaneal tuberosity $(48.3 \%)$ with the mean distance of $2.67 \pm 19.79 \mathrm{~mm}$ (Tables 1, 2). There was no significant difference be-

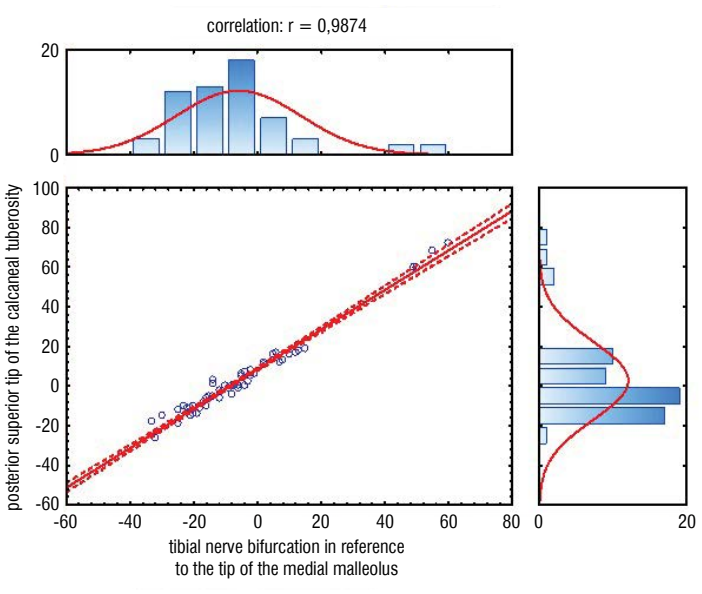

Figure 2. Correlation of the reference lines according to the tibial nerve bifurcation.

tween the sexes ( $p>0.05)$. The correlation between the reference lines of the tip of the medial malleolus and the posterior superior tip of the calcaneal tuberosity has been proven to be statistically significant $(r=0.9874, p<0.05)$ (Fig. 2).

The medial calcaneal branches were identified in the range from one to three ramifications. A total of 80 medial calcaneal branches were visualised. In 44 (73.3\%) patients, only one medial calcaneal branch was identified with no significant differences between the sexes ( $p>0.05$ ). Two medial calcaneal branches were presented in 12 patients, and three branches in 4 patients (Table 3 ). Most commonly medial calcaneal 
Table 3. Division of the medial calcaneal nerve according to the number of branches

\begin{tabular}{lcccc}
\hline Number of branches & Male feet $(\mathbf{n}=\mathbf{2 8})$ & Female feet $(\mathbf{n}=\mathbf{3 2})$ & Pooled sexes feet $(\mathbf{n}=\mathbf{6 0})$ & Percentage \\
\hline One & $16(57.1 \%)$ & $28(87.5 \%)$ & 44 & $73.3 \%$ \\
Two & $10(35.7 \%)$ & $2(6.3 \%)$ & 12 & $20 \%$ \\
Three & $2(7.1 \%)$ & $2(6.3 \%)$ & 4 & $6.7 \%$ \\
\hline
\end{tabular}

Table 4. Pattern of the medial calcaneal branches presentation according to the nerve of origin

\begin{tabular}{lcccc}
\hline Nerve of origin & Male feet $(\mathbf{n}=\mathbf{2 8})$ & Female feet $\mathbf{( n = 3 2 )}$ & Pooled sexes feet $\mathbf{( n = 6 0 )}$ & Percentage \\
\hline Single branch of TN & $14(50.0 \%)$ & $22(68.8 \%)$ & 36 & $60 \%$ \\
Single branch of LPN & $2(7.1 \%)$ & $5(15.6 \%)$ & 7 & $11.7 \%$ \\
One branch of TN and one of LPN & $6(21.4 \%)$ & $0(0.0 \%)$ & 6 & $10 \%$ \\
Two branches of TN & $3(10.7 \%)$ & $1(3.1 \%)$ & 4 & $6.7 \%$ \\
Two branches of TN and one of MPN & $0(0.0 \%)$ & $2(6.3 \%)$ & 2 & $3.3 \%$ \\
Two branches of TN and one of LPN & $2(7.1 \%)$ & $0(0.0 \%)$ & 2 & $3.3 \%$ \\
One branch of TN and one of MPN & $1(3.6 \%)$ & $1(3.1 \%)$ & 1 & $3.3 \%$ \\
Single branch of MPN & $0(0.0 \%)$ & $1(3.1 \%)$ & & $1.7 \%$ \\
\hline
\end{tabular}

TN — tibial nerve; LPN — lateral plantar nerve; MPN — medial plantar nerve

Table 5. Location of all medial calcaneal branches according to the reference lines [mm]

\begin{tabular}{lccccccc}
\hline Reference line & Location & $\mathbf{N}=\mathbf{7 8}$ & Percentage & Mean & Median & Maximum & Minimum \\
\hline Tip of the medial malleolus & Above the reference line & 25 & $31.25 \%$ & & & & -35 \\
& At the level of the reference line & 7 & $8.75 \%$ & -3.97 & -3 & 23 & \\
& Below the reference line & 48 & $60.0 \%$ & & & & 34 \\
Posterior superior tip of the & Above the reference line & 56 & $70.0 \%$ & & & -29 \\
calcaneal tuberosity & At the level of the reference line & 2 & $2.5 \%$ & 4.36 & 5 & & \\
& Below the reference line & 22 & $27.5 \%$ & & & \\
\hline
\end{tabular}

Two maximum distal locations were excluded from the statistics $(330 / 335 \mathrm{~mm}, 337 / 343 \mathrm{~mm})$

branch originated from the tibial nerve as a single branch (60\%). If there were two medial calcaneal branches, they emerged from the tibial and lateral plantar nerve most frequently (Table 4). Most of the medial calcaneal branches were located below the tip of the medial malleolus with the mean distance of $3.97 \mathrm{~mm}$ and above the posterior superior tip of the calcaneal tuberosity with the mean distance of $4.36 \mathrm{~mm}$ (Table 5). It may be assumed that majority of branches were located between the tip of the medial malleolus and the posterior superior tip of the calcaneal tuberosity.

First medial calcaneal branch $(n=60)$ originated $9.27 \pm 61.73 \mathrm{~mm}$ above the tip of the medial malleolus and $17.67 \pm 61.18 \mathrm{~mm}$ above the posterior superior tip of the calcaneal tuberosity with no statistically significant differences between the sexes ( $p>0.05$ ) (Table 6). Second medial calcaneal branch
( $n=16$ ) originated $9.50 \pm 10.09 \mathrm{~mm}$ below the tip of the medial malleolus and $1.63 \pm 11.28 \mathrm{~mm}$ below the posterior superior tip of the calcaneal tuberosity. Third medial calcaneal branch $(n=4)$ originated $11.75 \pm$ $\pm 9.03 \mathrm{~mm}$ below the tip of the medial malleolus and $4.00 \pm 8.45 \mathrm{~mm}$ below the posterior superior tip of the calcaneal tuberosity (Table 2, Figs. 3, 4). In 1 volunteer ( $n=2$ feet) an exceptionally long distance of the first medial calcaneal branch was measured: $330 \mathrm{~mm}$ on the left lower limb and $337 \mathrm{~mm}$ on the right lower limb above the tip of the medial malleolus and respectively $335 \mathrm{~mm}$ and $343 \mathrm{~mm}$ above the posterior superior tip of the calcaneal tuberosity.

\section{DISCUSSION}

Up to $15 \%$ of adult population suffers from the plantar heel pain [3]. According to Oztuna et al. [32], nerve entrapment is one of the reasons for this 
Table 6. First medial calcaneal branch location in relation to reference according to the sex

\begin{tabular}{lccccccccc}
\hline Reference line & Sex & $\mathbf{N}$ & $\begin{array}{c}\text { Mean } \pm \text { stand- } \\
\text { ard deviation }\end{array}$ & Median & Maximum & $\begin{array}{c}\text { Minimum } \\
\text { Lower }\end{array}$ & $\begin{array}{c}\text { Upper } \\
\text { quartile } \\
\text { (01) }\end{array}$ & $\begin{array}{c}\text { Puartile } \\
\text { (03) }\end{array}$ & Correlation \\
\hline $\begin{array}{l}\text { Tip of the medial } \\
\text { malleolus }\end{array}$ & Female & 32 & $-0.91 \pm 11.51$ & -0.5 & 23.0 & -22 & -8.5 & 6.0 & 0.9409 \\
& Male & 28 & $20.89 \pm 88.95$ & -1.5 & 337.0 & -27 & -6.5 & 6.5 & \\
$\begin{array}{l}\text { Posterior superior tip of } \\
\text { the calcaneal tuberosity }\end{array}$ & Female & 32 & $7.56 \pm 12.03$ & 6.5 & 34.0 & -16 & 3.5 & 14.5 & 0.9463 \\
& Male & 28 & $29.21 \pm 88.05$ & 7.0 & 343.0 & -17 & 2.0 & 13.0 & 0.8939 \\
\hline
\end{tabular}

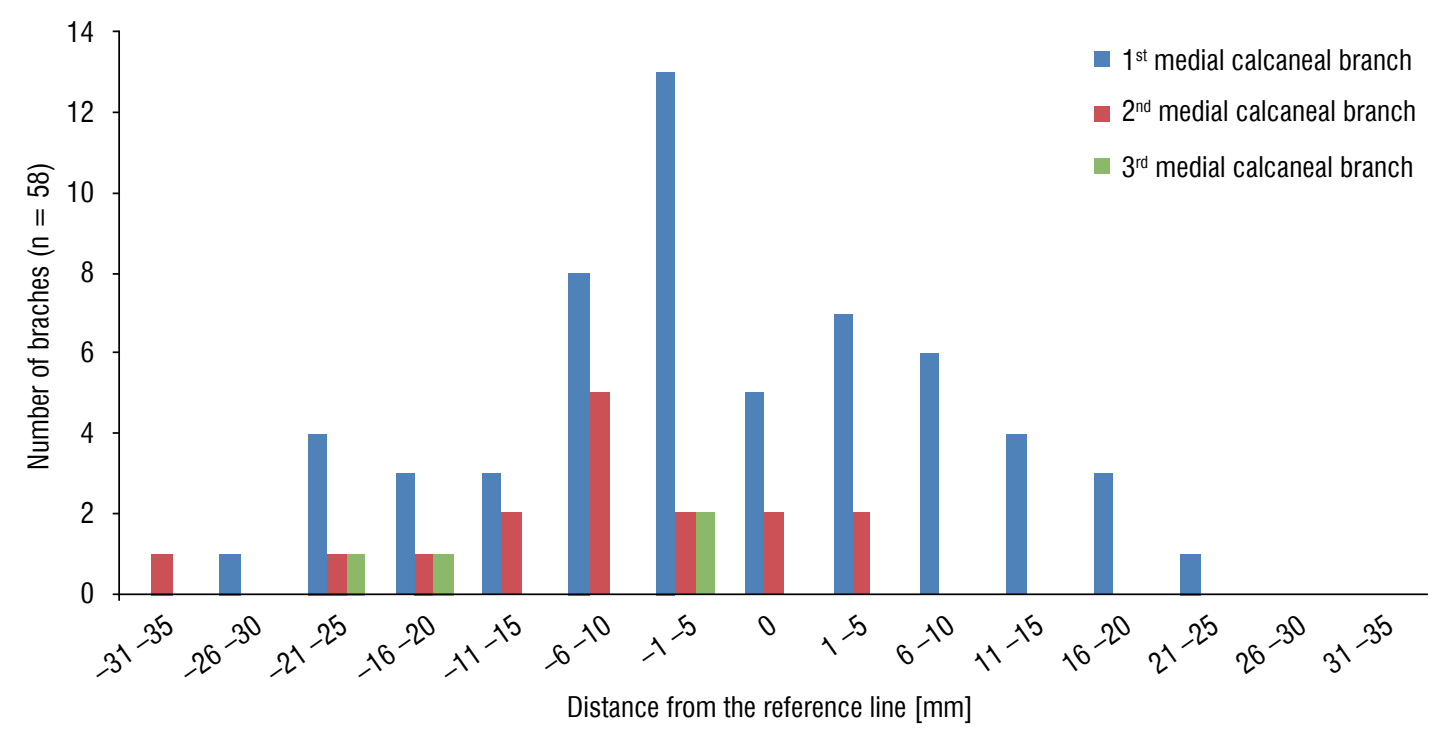

Figure 3. Medial calcaneal branches location in relation to the medial malleolus; two maximum distal locations were not included in the table (330 mm, $337 \mathrm{~mm})$.

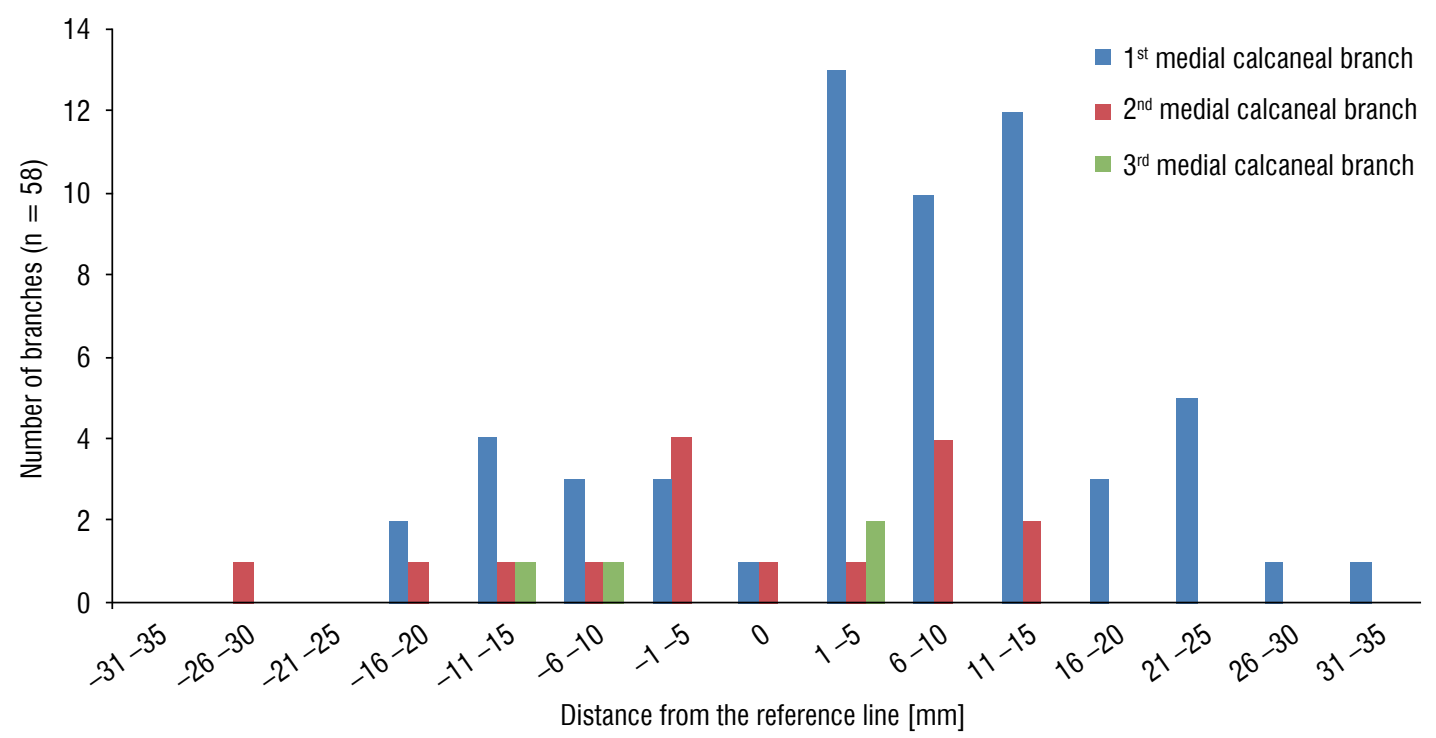

Figure 4. Medial calcaneal branches location in relation to the posterior superior tip of the calcaneal tuberosity; two maximum distal locations were not included in the table $(335 \mathrm{~mm}, 343 \mathrm{~mm})$. 
condition. As operative decompression of the tarsal tunnel is one of the most effective treatment options it is essential to perform the surgery in concordance with the anatomical structures in order to avoid its iatrogenic injury [12].

The first description of the tibial nerve and its branches variable anatomy was published by Horwitz [17] in 1938. Dissecting 100 lower extremities author states that the tibial nerve bifurcation occurs $1.3 \mathrm{~cm}$ above the tip of the medial malleolus. As for the medial calcaneal branch(es), he underlines its difference in number, location and origin. Dellon et al. [10] in 1984 examined 31 cadaver feet. For the first time the malleolar-calcaneal axis (MCA) was proposed as the reference line for the measurements. In $90 \%$ of the cases the tibial nerve bifurcation occurred within $1 \mathrm{~cm}$ of the MCA. Medial calcaneal branch originates above the flexor retinaculum in $65 \%$ of cases. The author emphasizes variability of left and right feet bifurcation locations as well as the number and location of the medial calcaneal branches. For the first time a substantial differences between mentioned studies are pointed out. Only $15 \%$ of Dellon et al. [10] cases presented the tibial nerve bifurcation at the level of Horwitz [17] results.

Comparing data obtained in the other published studies, the tibial nerve bifurcation was located inside the tarsal tunnel in $99.9 \%$ (Joshi et al. [21]), 93\% (Havel et al. [15]), 88\% (Torres et al. [37]) and $73 \%$ (Louisa et al. [27]) of cases. Heimkes et al. [16] defined the tarsal tunnel as the oval osteofibrous canal between talus, calcaneus and flexor retinaculum which stretches from the medial malleolus to the calcaneus. These data correspond with the results of the present study in which $76.7 \%$ of cases presented the bifurcation below the tip of the medial malleolus with the mean distance of $5.93 \pm 19.59 \mathrm{~mm}$. According to the tarsal tunnel definition it may be assumed that majority of the nerves (tibial nerve, lateral and medial plantar nerve) localised by the authors run and divide in the tarsal tunnel where it may by compressed.

Location of the tibial nerve bifurcation was the subject of many cadaveric studies [37]. Most of them were conducted according to the MCA reference line which was fixed between the centre of the medial malleolus and the medial calcaneal tuberosity $[21,27]$. Some authors suggest the tip of the lateral malleolus as the reference point which is localised below the tip of the medial malleolus [26, 38]. Nevertheless, in the present study the authors introduced different, parallel to the foot plane reference lines: a line crossing the tip of the medial malleolus and a line crossing the posterior superior tip of the calcaneal tuberosity. Measurement according to those two reference lines proved to have a high correlation $(r=0.9874)$. The authors believe that those bony, easy palpable through skin orientation points may appear of better use in the clinic environment.

Many authors published various results in relation to the number, location and origin of the medial calcaneal branches. Havel et al. [15], Louisa et al. [27] reported the occurrence of the range of one to two branches of the medial calcaneal nerves. Other published studies states the occurrence of the range of one to three (Torres et al. [37]) and even four (Joshi et al. [21]) branches of the medial calcaneal nerves. Single medial calcaneal branch is the most often finding in reports from Havel et al. [15] and Torres et al. [37] whilst two branches are most commonly registered by Louisa et al. [27] and Dellon et al. [10]. Joshi et al. [21] found single medial calcaneal branch in the same number of dissected lower limbs as for two branches. In the present study the authors visualised a range of one to three medial calcaneal branches with the most common single branch $(73.3 \%$ of the lower limbs) which is similar to reports by Torres et al. [37] and Havel et al. [15].

In the range of differences, the authors of all other publications indicated the tibial nerve as the most frequent nerve of origin for the medial calcaneal branch(es) $[15,21,27,37]$. The present study states that despite there is a single, double or triple branching pattern the tibial nerve is the most often nerve of origin ( $87 \%$ of cases). As for other ramification models, the lateral plantar nerve gives off medial calcaneal branch(es) in $25 \%$ of cases followed by medial plantar nerve present in $8 \%$ of cases. Some authors finds medial calcaneal branch(es) originating only from the tibial nerve [35], others claim it goes off only form the tibial or lateral plantar nerve $[14,17$, $21,23]$, yet another reports it originates only from the tibial or medial plantar nerve [4].

Medial calcaneal branch(es) location also appears to be a matter of variance among published studies. Some authors observes majority of the medial calcaneal ramifications proximally to the tarsal tunnel $[7,27,37]$, others locate it distally $[9,14]$. In the 
present study the authors registered $60 \%$ of medial calcaneal branches located below the tip of the medial malleolus at the same time $70 \%$ of them is located above posterior superior tip of the calcaneal tuberosity. It allows assuming that most of the ramifications are located between the two reference lines.

As a single case of an exceptionally distant location of the medial calcaneal branch of $330 \mathrm{~mm}$ and $337 \mathrm{~mm}$ above the tip of the medial malleolus may appear odd or suggest examiners mistake. It finds confirmation with Torres et al. [37] study where the authors also report a maximal ramification occurring $346.6 \mathrm{~mm}$ above the MCA.

Iborra et al. [18, 19] and Mullick et al. [29] confirm that the use of ultrasound in the tarsal tunnel syndrome operative treatment leads to respectively $90.12 \%$ and $93 \%$ excellent and good results. In the cadaveric study the authors proved that a high-resolution ultrasonography can visualize the entire course of the tibial nerve as well as its tiny branches which may be applied in the decompression surgeries $[18,19$, 29]. Also a sonosurgery, which is a "minimally invasive surgical technique performed with the continuous ultrasound imagining and the use of endoscopic tools" seems promising in improving the surgical result by reducing the risk of iatrogenic injuries [34].

\section{Limitations of the study}

The fact that tibial nerve and its branches run together with vessels between muscles and other anatomical structures may mean that its localisation changes during the lower limb movement. Therefore for the sake of this study a standardised positioning set up was arranged with all patients lying prone with the foot in neutral position (ankle fixed in the foot stabilising device and adjusted to the right angle). Second limitation is the localisation of the posterior superior tip of the calcaneal tuberosity, which depends on the foot arch. The angle between calcaneal inclination line and the horizontal line (heel pitch angle) varies in cavus, neutral and flat foot. Therefore in cavus foot the measured distance may be longer whilst shorter in the flat foot. Another restriction is a limited ultrasound resolution. Although authors were able to track the tibial nerve till its final bifurcation the high frequency ultrasound might miss some tiny terminal nerves, such as medial calcaneal branches. To reduce this factor ultrasound examination was conducted by an experienced orthopaedic surgeon.

\section{CONCLUSIONS}

To conclude, the authors of the present study together with the other analysed publications proved that the anatomy of the tibial nerve and its distal branches observed in the medial ankle area is different between left and right limbs, gender and amongst individuals. As is the origin, location and division pattern on the medial calcaneal branch(es). Because of these anatomical variations, it is difficult to suggest any safe zone area for the medial ankle surgical treatment, as so the preoperative or intraoperative ultrasound examination is highly recommended.

\section{REFERENCES}

1. Ahmad M, Tsang K, Mackenney PJ, et al. Tarsal tunnel syndrome: a literature review. Foot Ankle Surg. 2012; 18(3): 149-152, doi: 10.1016/j.fas.2011.10.007, indexed in Pubmed: 22857954.

2. Aldridge T. Diagnosing heel pain in adults. Am Fam Physician. 2004; 70(2): 332-338, indexed in Pubmed: 15291091.

3. Alshami AM, Souvlis T, Coppieters MW. A review of plantar heel pain of neural origin: differential diagnosis and management. Man Ther. 2008; 13(2): 103-111, doi: 10.1016/j. math.2007.01.014, indexed in Pubmed: 17400020.

4. Andreasen Struijk LNS, Birn H, Teglbjaerg PS, et al. Size and separability of the calcaneal and the medial and lateral plantar nerves in the distal tibial nerve. Anat Sci Int. 2010; 85(1): 13-22, doi: 10.1007/s12565-009-0045-y, indexed in Pubmed: 19449089.

5. Bailie DS, Kelikian AS. Tarsal tunnel syndrome: diagnosis, surgical technique, and functional outcome. Foot Ankle Int. 1998; 19(2): 65-72, doi: 10.1177/107110079801900203, indexed in Pubmed: 9498577.

6. Bilge O, Ozer MA, Govsa F. Neurovascular branching in the tarsal tunnel. Neuroanatomy. 2003; 2: 39-41.

7. Davis TJ, Schon LC. Branches of the tibial nerve: anatomic variations. Foot Ankle Int. 1995; 16(1): 21-29, doi: 10.1177/107110079501600105, indexed in Pubmed: 7697149.

8. De Maeseneer M, Madani H, Lenchik L, et al. Normal anatomy and compression areas of nerves of the foot and ankle: US and MR imaging with anatomic correlation. Radiographics. 2015; 35(5): 1469-1482, doi: 10.1148/ rg.2015150028, indexed in Pubmed: 26284303.

9. Dellon $\mathrm{AL}$, Kim J, Spaulding CM. Variations in the origin of the medial calcaneal nerve. J Am Podiatr Med Assoc. 2002; 92(2): 97-101, doi: 10.7547/87507315-92-2-97, indexed in Pubmed: 11847261.

10. Dellon $A L$, Mackinnon SE. Tibial nerve branching in the tarsal tunnel. Arch Neurol. 1984; 41(6): 645-646, doi: 10.1001/archneur.1984.04210080053013, indexed in Pubmed: 6721738.

11. Didia BC, Horsefall AU. Medial calcaneal nerve. An anatomical study. J Am Podiatr Med Assoc. 1990; 80(3): 115-119, doi: 10.7547/87507315-80-3-115, indexed in Pubmed: 2332828.

12. Doneddu PE, Coraci D, Loreti C, et al. Tarsal tunnel syndrome: still more opinions than evidence. Status 
of the art. Neurol Sci. 2017; 38(10): 1735-1739, doi: 10.1007/s10072-017-3039-x, indexed in Pubmed: 28664501.

13. Flanigan RM, DiGiovanni BF. Peripheral nerve entrapments of the lower leg, ankle, and foot. Foot Ankle Clin. 2011; 16(2): 255-274, doi: 10.1016/j.fcl.2011.01.006, indexed in Pubmed: 21600446.

14. Govsa F, Bilge O, Ozer MA. Variations in the origin of the medial and inferior calcaneal nerves. Arch Orthop Trauma Surg. 2006; 126(1): 6-14, doi: 10.1007/s00402-0050088-z, indexed in Pubmed: 16333630.

15. Havel PE, Ebraheim NA, Clark SE, et al. Tibial nerve branching in the tarsal tunnel. Foot Ankle. 1988; 9(3): 117-119, doi: 10.1177/107110078800900304, indexed in Pubmed: 2852629.

16. Heimkes B, Posel P, Stotz S, et al. The proximal and distal tarsal tunnel syndromes. An anatomical study. Int Orthop. 1987; 11(3): 193-196, doi: 10.1007/BF00271447, indexed in Pubmed: 3623755.

17. Horwitz MT. Normal anatomy and variations of the peripheral nerves of the leg and foot application in operations for vascular diseases: study of one hundred specimens. Arch Surg. 1938; 36(4): 626-636, doi: 10.1001/archsurg.1938.01190220068005.

18. Iborra A, Villanueva M, Sanz-Ruiz P. Results of ultrasound-guided release of tarsal tunnel syndrome: a review of 81 cases with a minimum follow-up of 18 months. J Orthop Surg Res. 2020; 15(1): 30, doi: 10.1186/s13018020-1559-1, indexed in Pubmed: 31992296.

19. Iborra A, Villanueva M, Barrett SL, et al. Anatomic delineation of tarsal tunnel innervation via ultrasonography. J Ultrasound Med. 2018; 37(6): 1325-1334, doi: 10.1002/ jum.14499, indexed in Pubmed: 29205431.

20. Iborra Á, Villanueva-Martínez M, Barrett SL, et al. Ultrasound-Guided release of the tibial nerve and its distal branches: a cadaveric study. J Ultrasound Med. 2019; 38(8): 2067-2079, doi: 10.1002/jum.14897, indexed in Pubmed: 30589453

21. Joshi SS, Joshi SD, Athavale AS. Anatomy of tarsal tunnel and its applied Significeance. J Anat Soc india. 2006; 55(1): 52-56.

22. Keck $C$. The tarsal-tunnel syndrome. J Bone Joint Surg. 1962; 44(1): 180-182, doi: 10.2106/00004623196244010-00015.

23. Kim DI, Kim YS, Han SH. Topography of human ankle joint: focused on posterior tibial artery and tibial nerve. Anat Cell Biol. 2015; 48(2): 130-137, doi: 10.5115/ acb.2015.48.2.130, indexed in Pubmed: 26140224.
24. Kopell HP, Thompson WA. [Peripheral entrapment neuropathies of the lower extremity]. N Engl J Med. 1960; 262: 56-60, doi: 10.1056/NEJM196001142620202, indexed in Pubmed: 13848498.

25. Lam SJ. A tarsal-tunnel syndrome. Lancet. 1962; 2(7270): 1354-1355, doi: 10.1016/s0140-6736(62)91024-3, indexed in Pubmed: 13928212.

26. Lijoi F, Lughi M, Baccarani G. Posterior arthroscopic approach to the ankle: an anatomic study. Arthroscopy. 2003; 19(1): 62-67, doi: 10.1053/jars.2003.50003, indexed in Pubmed: 12522404.

27. Louisia S, Masquelet AC. The medial and inferior calcaneal nerves: an anatomic study. Surg Radiol Anat. 1999; 21(3): 169-173, doi: 10.1007/BF01630895, indexed in Pubmed: 10431329.

28. Moore KL. Clinically oriented anatomy. 8th Ed, LWW 2017.

29. Mullick T, Dellon AL. Results of decompression of four medial ankle tunnels in the treatment of tarsal tunnels syndrome. J Reconstr Microsurg. 2008; 24(2): 119-126, doi: 10.1055/s-2008-1076089, indexed in Pubmed: 18459088.

30. Ndiaye A, Dia A, Konate I, et al. [Topographic anatomy of the tibial nerve in the medial malleolus: application to the effect of nerve block anesthesia]. Morphologie. 2003; 87(277): 25-27, indexed in Pubmed: 14717067.

31. Netter FH. Atlas of human anatomy. 7th Ed, Elsevier 2018.

32. Oztuna V, Ozge A, Eskandari MM, et al. Nerve entrapment in painful heel syndrome. Foot Ankle Int. 2002; 23(3): 208-211, doi: 10.1177/107110070202300304, indexed in Pubmed: 11934062.

33. Paulsen $F$, Waschke J. Sobotta atlas of human anatomy. 15th Ed, Urban \& Fischer 2012.

34. Pilecki Z, Pilecki G, Bubnov R. Introduction to sonosurgery. EPMA J. 2014; 5(S1), doi: 10.1186/1878-5085-5-s1-a66.

35. Rondhuis JJ, Huson A. The first branch of the lateral plantar nerve and heel pain. Acta Morphol Neerl Scand. 1986; 24(4): 269-279, indexed in Pubmed: 3425404.

36. Rowley WR, Bezold C, Arikan Y, et al. Diabetes 2030: Insights from Yesterday, Today, and Future Trends. Popul Health Manag. 2017; 20(1): 6-12, doi: 10.1089/ pop. 2015.0181, indexed in Pubmed: 27124621.

37. Torres ALG. Marcus Castro Ferreira MC. Study of the anatomy of the tibial nerve and its branches in the distal medial leg. Acta Ortop Bras. 2012; 20(3): 157-164.

38. Warchoł $Ł$, Mróz I, Mizia E, et al. Vascular density of inferior tibiofibular joint: cadaveric experimental study. Folia Med Cracov. 2017; 57(1): 47-54, indexed in Pubmed: 28608862.

39. Yates B. Merriman's Assessment of the Lower Limb. 3rd Ed. Churchill Livingstone, New York 2008. 